$\begin{array}{lllll}\text { C } & & \text { A } & & \text { S } \\ \text { R } & \text { E } & \text { P } & \text { O } & \text { R }\end{array}$

James HL Tsu 徐學良
SK Yuen 袁仕傑
H Cheung 張 恆
YW Lee 李日榮
PL Liu 廖柏寧
E

$\mathrm{T}$

\title{
Erdheim-Chester disease: an uncommon cause of upper urinary tract obstruction
}

Erdheim-Chester disease is a rare non-Langerhans form of systemic histiocytosis of unknown origin. We describe a 45 -year-old man presenting with bilateral hydronephrosis suggestive of extrinsic urinary tract obstruction. Computed tomography revealed extensive hypodense soft tissue infiltration in the retroperitoneum surrounding the kidneys. Needle biopsy of the retroperitoneal soft tissue revealed aggregates of lipid-laden histiocytes expressing CD68 but negative for CD1a and S100 protein. The diagnosis of Erdheim-Chester disease was supported by typical radionuclide bone scinitigraphic findings. Treatment with prednisolone, sirolimus, and regular ureteric stent revision was initiated to achieve adequate urinary tract drainage. To our knowledge, this is the second patient with Erdheim-Chester disease reported in Hong Kong. A high index of suspicion is required to avoid delay in the diagnosis of this rare disease.

\section{Introduction}

Erdheim-Chester disease (ECD) is a rare, non-inherited, non-Langerhans form of systemic histiocytosis of unknown origin. It is characterised by xanthogranulomatous infiltration in various organ systems. We report a patient who presented with urinary tract obstruction due to this disease.

\section{Case report}

A 45-year-old man with good past health was referred to the Caritas Medical Centre in 1999 for management of hypertension. Workup for secondary causes and end-organ damage were negative, except that bilateral hydronephrosis was noted on ultrasonography. He was asymptomatic and physical examination was otherwise unremarkable. Renal function was normal and urine contained bland sediments without proteinuria. Plain radiography revealed no urolithiasis. Excretory urography and retrograde pyelography showed bilateral hydronephrotic kidneys with distorted and dilated pelvicalyceal systems from extrinsic compressions at the levels of the renal pelves and proximal ureters. Contrast computed tomography $(\mathrm{CT})$ revealed irregular retroperitoneal hypodense soft tissues surrounding the major vessels and kidneys, compressing the renal pelvis on both sides (Fig 1). The bilateral CT-guided biopsies of perinephric tissue were performed but yielded only dense collagenous fibrous tissue with scanty inflammatory cells. No histological diagnosis could be made but the patient refused further biopsy. From August 2000 to January 2004, he was treated as having idiopathic retroperitoneal fibrosis with prednisolone, azathioprine, and methotrexate. However, his C-reactive protein and erythrocyte sedimentation rate

Key words

Erdheim-Chester disease; Histiocytosis Sirolimus

Hong Kong Med J 2013;19:451-4 DOI: $10.12809 / \mathrm{hkmj} 133738$

Caritas Medical Centre, 111 Wing Hong Street, Shamshuipo, Kowloon, Hong Kong:

Department of Surgery

JHL Tsu, FRCS (Urology), FHKAM (Surgery)

PL Liu, FRCS (Urology), FHKAM (Surgery) Department of Medicine and Geriatrics SK Yuen, FHKCP, FHKAM (Medicine) Department of Pathology H Cheung, $\mathrm{MB}, \mathrm{ChB}$ Department of Radiology

YW Lee, FRCR (UK), FHKAM (Radiology)

Correspondence to: Dr JHL Tsu Email: thl589@ha.org.hk showed an inconsistent response, which was also complicated by acne, fluid retention, and leukopenia. Another CT abdomen early in 2005 found no significant change in the perinephric lesions but the hydrocalices on the left had increased. Diuretic radionuclide scintigraphy confirmed the presence of obstruction to urine drainage at the level of left proximal ureter, whilst drainage of the right kidney was normal. Medical treatment was discontinued but the patient refused surgical intervention to relieve his ureteric obstruction.

He noticed right mechanical knee pain since February 2007. Plain radiographs showed symmetrical sclerotic changes in distal femoral shafts and upper tibias, raising the possibility of ECD, in view of the history of retroperitoneal fibrosis. Magnetic resonance imaging of his right knee showed abnormal marrow signals with enhancement at the distal femur and proximal tibia, suggestive of primary diffuse bone disease. An arthroscopic biopsy of the tibial plateau was performed but only showed bone necrosis with empty lacunae and inter-trabecular fibroblastic tissues. The patient declined total knee replacement and was prescribed simple analgesics.

Nine years after his initial presentation, an 8-mm right ureteral calculus with partial obstruction was revealed by CT. He therefore agreed to ureteroscopic lithotripsy 


\section{不尋常的上尿道阻塞原因：埃德海姆一 徹斯特病}

埃德海姆一徹斯特病是一種罕見的非朗格漢斯細胞的組織細胞疾病。 本文描述一名45歲男子其最初病徵為雙側腎水腫。電腦掃描發現在病 人後腹腔有廣泛的低密度軟組織浸潤包圍雙側腎。軟組織經皮細針穿 刺切片發現內吞噬脂肪的組織細胞, CD68呈陽性，但CD1a及S100 蛋白質則呈陰性。病者的近乎示病性核素骨顯像也支持其埃德海姆一 徹斯特病的診斷。患者正接受類固醇及西羅莫司治療, 以及定期更換 輸尿管導管以舒緩上尿道因病的阻塞。據我們所知, 這是香港第二宗 埃德海姆一徹斯特病病例報告。面對這罕見但嚴重的病症時, 高度警 覺能避免診斷上的延誤。

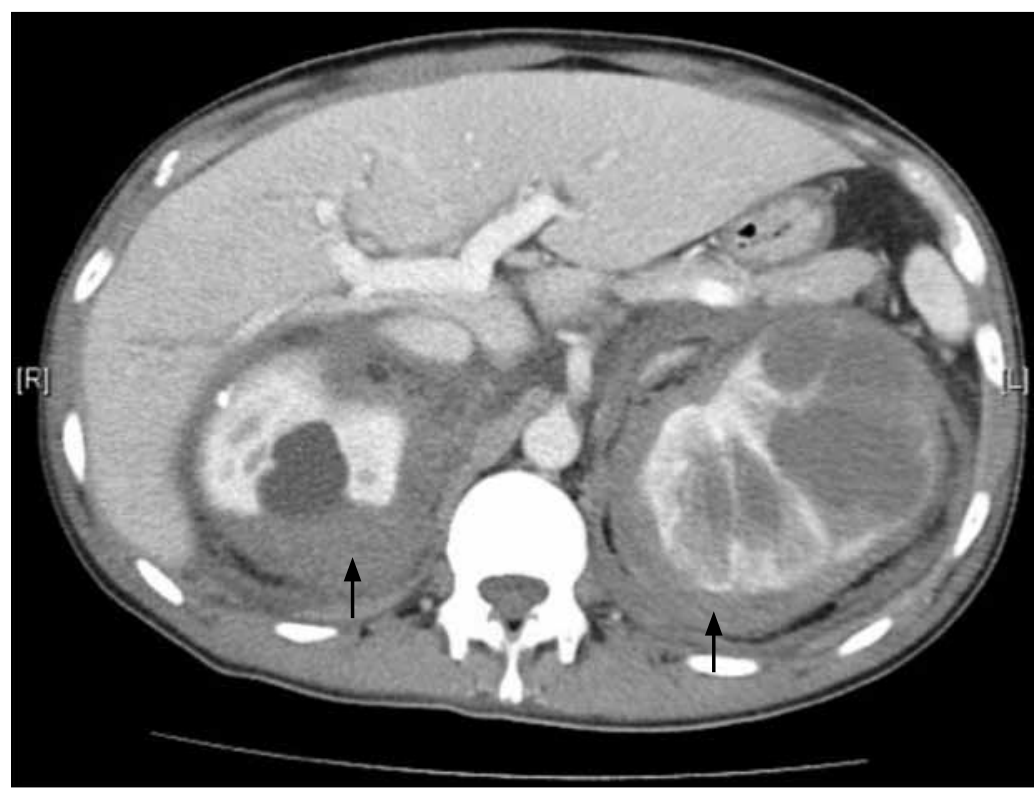

FIG I. Computed tomography of the retroperitoneum shows hypodense soft tissue surrounding kidneys and renal pelvis on both sides

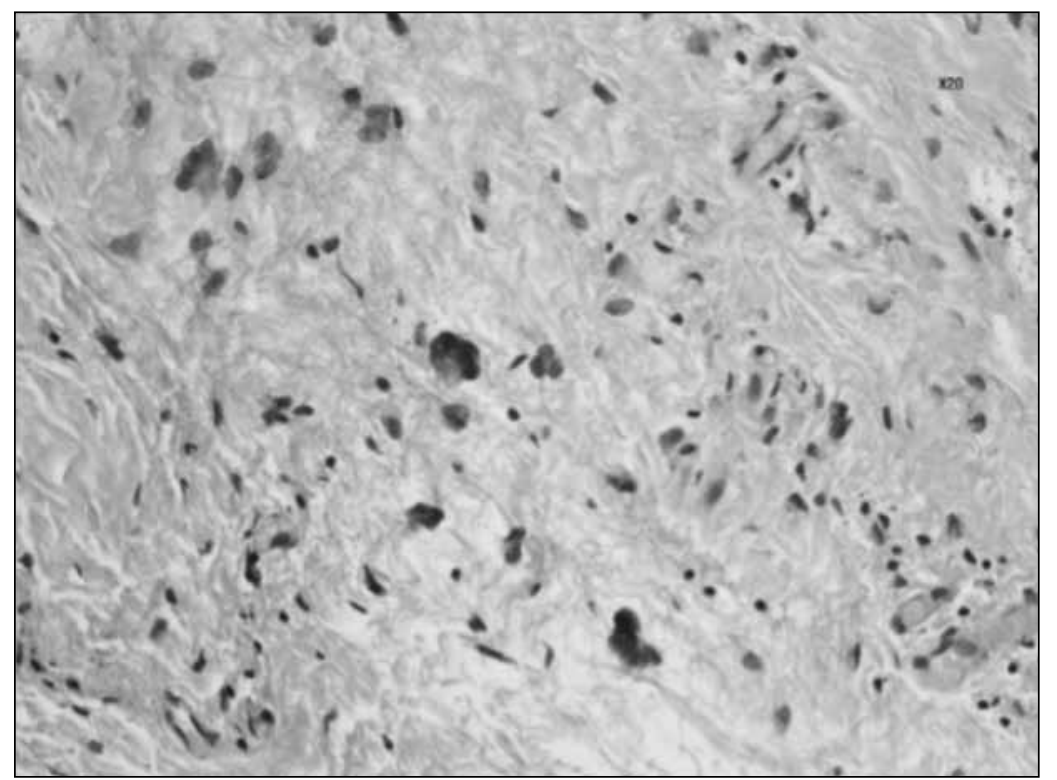

FIG 2. Retroperitoneal biopsy shows aggregates of foamy histiocytes and lymphocytes without Touton giant cells $(\mathrm{H} \& \mathrm{E}, \mathrm{x} 20)$ and ureteral stenting to relieve his left proximal ureteral obstruction, as well as a further CT-guided retroperitoneal biopsy. Amidst fibrous tissue, this biopsy yielded aggregates of foamy histiocytes and lymphocytes without Touton giant cells (Fig 2). Immunohistochemical studies showed that the foamy cells were positive for CD68, and negative for CD1a and S100 proteins. Whole-body bone scintigraphy showed markedly increased tracer uptake over the long bones typical of ECD. A F18-fluorodeoxyglucose (FDG) whole-body positron emission scan revealed increased soft tissue density without hypermetabolic activity in the anterior mediastinum around the ascending aorta and pulmonary trunk, as well as the retroperitoneal (para-aortic) and bilateral perinephric soft tissues. No lymphadenopathy or malignant lesion was seen. There were also areas of diffuse bony scleroses with very mild FDG uptake involving the skull vault, facial bones, clavicles, and long bones. A clinicopathological diagnosis of ECD was therefore made.

An echocardiogram showed trivial mitral and tricuspid regurgitation but no feature of restrictive heart disease. Lung function test showed normal forced expiratory volumes and vital capacity. The CT thorax revealed mild emphysematous changes only. After detailed discussion of available treatment options, the patient started taking prednisolone 0.35 $\mathrm{mg} / \mathrm{kg} /$ day and sirolimus (targeted trough level of 8-12 $\mathrm{ng} / \mathrm{mL}$ ). The plan was to have regular revisions of ureteric stents and serial radiological imaging to monitor his disease progress.

\section{Discussion}

Erdheim-Chester disease was first described in 1930 by William Chester and his mentor Jakob Erdheim as a form of lipid granulomatosis, distinctive from other histiocytic disorders such as Hand-Schüller-Christian disease. ${ }^{1}$ It is a very rare form of non-familial, nonLangerhans systemic histiocytosis of unknown origin and characterised by tissue infiltration by abnormal histiocytes. About 250 cases had been reported in the literature as at September 2007..$^{2}$ In Hong Kong, the first case was reported in 2007 in a patient with unilateral proptosis. ${ }^{3}$ To our knowledge, our patient was the second to be reported in Hong Kong.

Unlike Langerhans cell histiocytosis ( $\mathrm{LCH})$ which usually occurs in children and adolescents, ECD primarily affects middle-aged to older adults (typically $>40$ years old) and has a slight male predominance. ${ }^{4}$ Its hallmark is bilateral symmetrical osteosclerosis resulting from histiocytic infiltration, affecting the diametaphysis of long bones in the appendicular skeleton with sparing of the epiphyses. Bone scintigraphy can demonstrate the virtually pathognomonic tracer uptake in affected bones. ${ }^{5}$ Bone pain is the commonest symptom in patients 
with ECD, with the femur, tibia, and fibula being most commonly affected. About half of patients have extraosseous infiltrative involvement. Organs affected may include the orbits (exophthalmos), lungs (interstitial lung disease), heart (pericardial infiltration), skin (xanthelasma), and central nervous system (causing diabetes insipidus, and ataxia). ${ }^{4}$

The kidneys and retroperitoneum are affected in about one third of patients but is rarely symptomatic, though dysuria, abdominal pain, ballotable kidneys, and ureteral obstruction leading to renal failure have been reported. ${ }^{4,6,7}$ Consistent with the literature, our patient was asymptomatic despite the ureteric obstruction. Retroperitoneal involvement in ECD manifests as either an obstructive uropathy-like picture due to xanthogranulomatous process, or nephropathy due to direct histiocytic infiltration. ${ }^{7}$ On CT, there is often bizarre compression of renal parenchyma and the pelvis from homogenous hypodense tissue infiltrates which show weak contrast enhancement in the perinephric and perirenal spaces (as in our patient). ${ }^{8,9}$ Infiltrating bands of variable thickness may form in the perirenal space, and generate a 'hairy kidney' appearance. ${ }^{10}$

In our patient, the constellation of retroperitoneal lesions, unexplained knee pain, and radiographic appearances raised the suspicion of ECD. A definitive diagnosis, however, depended on histological confirmation. Microscopically, there was xanthomatous or xanthogranulomatous tissue infiltration by foamy histiocytes or lipidladen macrophages surrounded by fibrosis. Immunohistochemically, the histiocytes are always positive for CD68 and negative for CD1a. Ultrastructural studies showed no Birbeck granules, in contrast to the histiocytes found in $\mathrm{LCH}$. The histiocytes of some ECD patients display positivity for S100 protein but others do not. ${ }^{11}$ To arrive at a diagnosis, tissues are commonly obtained from either the bone or the retroperitoneum. In our patient, initial biopsy of perinephric tissue was not diagnostic, probably due to inadequate sampling. It has been reported that tissues obtained by percutaneous biopsy might be erroneously diagnosed as idiopathic retroperitoneal fibrosis or labelled inconclusive. ${ }^{12}$ Fortunately, our patient agreed to a repeat biopsy 9 years after his initial presentation, finally enabling the diagnosis of ECD to be established.

In our patient, initially expectant management was adopted despite presence of obstruction. It was only until urolithiasis and progressive ureteral obstruction supervened that our patient agreed for surgical intervention. Although conservative treatment might lead to good outcomes in selected cases of retroperitoneal obstructive ECD, most authorities advocate drainage of the obstructed system by ureteral stenting or percutaneous nephrostomy. Definitive surgical intervention for obstructive retroperitoneal lesion using open and laparoscopic means have been reported but with variable results. ${ }^{8,12}$

Clinical trials on the definitive treatment of ECD are lacking, thus therapeutic options can only be based on anecdotal experience. Systemic corticosteroids, cytotoxic chemotherapy, and radiation have been used with variable success. ${ }^{4,13,14}$ Despite normal renal function in our patient, his debilitating knee pain and slow but definite progression of ECD-induced obstructive uropathy prompted consideration of pharmacotherapy. Our patient showed poor tolerance to high-dose prednisolone and refused interferon treatment. After discussion, he was started on low-dose prednisolone and sirolimus. Sirolimus, with its anti-fibrotic and anti-proliferative properties, has been used with success in ECD. ${ }^{15} \mathrm{~A}$ study is currently on-going in Parma, Italy, looking at the use of this agent in ECD patients with respect to progression-free survival and disease remission (personal communication).

The prognosis of ECD depends heavily on the extent and distribution of extraosseous disease. ${ }^{7}$ In a large review, death occurs in $57 \%$ of cases within 3 years of the diagnosis. Soft tissue and organ diseases were noted to be indicators of poor outcomes, especially when the heart and lungs were involved. ${ }^{4}$ In our patient, echocardiography and thoracic CT showed no disease and he displayed good tolerance to treatment. Owing to the rarity of this disease, the efficacy of our treatment and long-term prognosis remain uncertain.

\section{Conclusion}

We report the second case of ECD in Hong Kong. Despite its rarity, it remains a serious condition with an uncertain prognosis owing to systemic involvement and lack of clinical trials regarding possible interventions. Clinicians should bear this diagnosis in mind when encountering patients with retroperitoneal upper urinary tract obstruction, especially when typical radiographic findings are present.

\section{References}

1. Chester W. Über lipoid granulomatose [in German]. 2. Taguchi T, Iwasaki Y, Asaba K, et al. Erdheim-Chester Virchows Arch Pathol Anat 1930;279:561-602. cross ref

disease: report of a case with PCR-based analysis of the 
expression of osteopontin and survivin in xanthogranulomas following glucocorticoid treatment. Endocr J 2008;55:21723. cross ref

3. Lau WW, Chan E, Chan CW. Orbital involvement in ErdheimChester disease. Hong Kong Med J 2007;13:238-40.

4. Veyssier-Belot C, Cacoub P, Caparros-Lefebvre D, et al. Erdheim-Chester disease. Clinical and radiologic characteristics of 59 cases. Medicine (Baltimore) 1996;75:157-69. cross ref

5. Núñez R, Tronco GG, Rini JN, et al. Radionuclide bone imaging in Erdheim-Chester disease. Clin Nucl Med 2005;30:32-4. cross ref

6. Yun EJ, Yeh BM, Yabes AP, Coakley FV, Kane CJ. ErdheimChester disease: case report and review of associated urological, radiological and histological features. J Urol 2003;169:1470-1. cross ref

7. Sanchez JE, Mora C, Macia M, Navarro JF. Erdheim-Chester disease as cause of end-stage renal failure: a case report and review of the literature. Int Urol Nephrol 2010;42:110712. cross ref

8. Wimpissinger TF, Schernthaner G, Feichtinger H, Stackl W. Compression of kidneys in Erdheim-Chester disease of retroperitoneum: open surgical approach. Urology 2005;65:798. cross ref
9. Mounach A, Nouijai A, Achemlal L, El Maghraoui A, Bezza A. Erdheim-Chester disease: a case report with pulmonary, kidney involvement and bone lesions. Rheumatol Int 2010;30:651-4. cross ref

10. Colin P, Ballereau C, Lambert M, Lemaitre L, Leroy X, Biserte J. Retroperitoneal infiltration as the first sign of ErdheimChester disease. Int J Urol 2008;15:455-6. cross ref

11. Haroche J, Amoura Z, Dion E, et al. Cardiovascular involvement, an overlooked feature of Erdheim-Chester disease: report of 6 new cases and a literature review. Medicine (Baltimore) 2004;83:371-92. cross ref

12. Castle EP, Humphreys MR, Andrews PE. Laparoscopic biopsy and ureterolysis in Erdheim-Chester disease. Mayo Clin Proc 2005;80:546-8. cross ref

13. Sheidow TG, Nicolle DA, Heathcote JG. Erdheim-Chester disease: two cases of orbital involvement. Eye (Lond) 2000;14:606-12. cross ref

14. Matsui K, Nagata Y, Hiraoka M. Radiotherapy for ErdheimChester disease. Int J Clin Oncol 2007;12:238-41. cross ref

15. Vaglio A, Moroni G, Greco P, et al. Treatment of ErdheimChester disease with sirolimus. Report of a case [abstracts]. European Renal Association-European Dialysis and Transplant Association Congress 2004;75-6. 